\title{
Conceptual frameworks for urban sustainability indicators - an empirical analysis
}

\author{
Halla, P., Merino-Saum, A.
}

\section{Authors details:}

Pekka Halla*, Laboratory for Human Environment Relations in Urban Systems (HERUS), Institute of Environmental Engineering (IIE), School of Architecture, Civil and Environmental Engineering (ENAC), Ecole Polytechnique Fédérale de Lausanne (EPFL), CH-1015, Lausanne, Switzerland, pekka.halla@epfl.ch.

Albert Merino-Saum, albert.merino@epfl.ch.

* Corresponding author

\begin{abstract}
Indicator-based assessment represents a popular means of operationalizing the concept of sustainability. A central yet often neglected aspect in the development of indicator sets concerns the elaboration of accompanying conceptual frameworks. Despite the pivotal role that such frameworks play, and the normative power they wield, little explicit guidance exists for their development. To address this issue, we analyze an extensive sample of conceptual frameworks drawn from 67 urban indicator initiatives. The results of the analysis elaborate an empirically-based typology of four principal and two emerging framework types, each based on a particular logic for creating conceptual categories for urban sustainability indicators. We also develop a comparison of the framework types in terms of their respective abilities to meet the different purposes that conceptual frameworks ideally serve in indicator set development. The results allow us to provide much-needed guidance for indicator set developers; first, by laying out the range of options available; second, by helping developers choose between types of frameworks in accordance with their particular aims. In addition, through analysis of how urban sustainability is de facto defined in indicator initiatives, we aim to make a conceptual contribution that advances our understanding of the meaning of this complex concept.
\end{abstract}

\section{Keywords}

Urban systems; sustainability; indicators; conceptual frameworks

\section{A revised manuscript published (Open Access) in Sustainable Development:}

Halla, P., \& Merino-Saum, A. (2022). Conceptual frameworks in indicator-based assessments of urban sustainability -An analysis based on 67 initiatives. Sustainable Development,30(5), 1056-1071. https://doi.org/10.1002/sd.2300 


\section{Introduction}

Over the last decades, the concept of sustainability has increasingly become more prominent in the strategies of both public and private sector actors. As part of this general concern, particular attention has been given to the sustainable development of urban areas (UN, 2017), which, due to their role as socio-economic hubs of human activity, constitute a crucial determinant of global sustainability (IPCC, 2014). To address this issue, a range of different actors from the international to the local scale have developed sets of indicators for measuring the sustainability of cities (Verma and Raghubanshi, 2018; Merino-Saum et al., 2020). Such indicator sets represent important means for the deployment of the complex concept of urban sustainability at a more concrete and operational level.

A central component in all sustainability indicator initiatives concerns the development of the accompanying conceptual frameworks (Pintér et al., 2012; Hák et al., 2016). These frameworks not only support the selection of indicators, but more fundamentally, they also contribute to the very definition of the concept (e.g. 'urban sustainability') being measured (Pintér et al., 2005; UN, 2007), which bestows them with tremendous normative power. Given the pivotal role of frameworks, it is surprising how little explicit guidance can be found in literature on how to suitably develop them (Burgass et al., 2017). Yet, each framework should be constructed with conscious consideration of the context and purposes of the indicator initiative in question (Munier, 2011), since simply copying frameworks from earlier initiatives can easily lead to the selection of indicators with poor resonance and usability for local decision-making (Nicholson et al., 2012).

Within the general lack of guidance for framework development, a more specific shortcoming concerns the vagueness around the options available when choosing between types of frameworks. To be precise, a number of authors have addressed the topic (Maclaren, 1996; Gallopín, 1997; Pintér et al., 2005; Olalla-Tárraga, 2006; Lyytimäki and Rosenström, 2008; Nathan and Reddy, 2012), but their work lacks a firm foundation on a systematic empirical review and comparison of the range of options available. As a result, current scholarship is missing an explicitly defined and empirically-based typology of frameworks that could support indicator set developers in the task of framework construction.

The aim of this research is to address this gap in current scientific knowledge by systematically analyzing and comparing conceptual frameworks used in connection with urban sustainability indicator sets, based on a comprehensive empirical sample of 67 such indicator initiatives from the previous decade. This work allows us to make several contributions to the field of urban sustainability assessment. First, we lay out the range of options available to indicator set developers, both in terms of types of frameworks as well as their internal categories. Second, in comparing types of frameworks we aim to clarify their respective abilities to serve different purposes. Finally, by revealing what is included and excluded in the analyzed conceptual frameworks, i.e., how the indicator initiatives de facto define the concept of 'urban sustainability', we aim to contribute to the discussion on the meaning of this complex concept.

The organization of the article is as follows. Section 2 begins by providing a theoretical foundation for understanding the characteristics and purposes of conceptual frameworks in sustainability indicator initiatives. Section 3 presents the empirical sample and the method by which it was analyzed. Section 4 presents the results of the analysis in the form of an elaborated empirically-based typology of conceptual frameworks for urban sustainability indicators. Section 5 discusses the findings and formulates recommendations for future set developers. Section 6 concludes the article with a brief summary and a look ahead. 


\section{Indicator frameworks - Theoretical background}

\subsection{What is an indicator framework?}

Although most reports and studies focusing on sustainability indicators allude to conceptual frameworks to some degree, concrete definitions are rarely provided. This reflects the general ambiguity that surrounds the term (Miles et al., 2014; Ravitch and Riggan, 2017). While for some a mere visual representation of a study's organization qualifies as a conceptual framework, for others it encompasses a broader set of elements, including a study's goals, theories and methods (Ravitch and Riggan, 2017). Therefore, there is a need to define what is meant by conceptual frameworks in the context of this article.

To that end, it is worth first making a distinction between procedural and conceptual frameworks (see Fig. 1). While procedural frameworks depict the methodology implemented to measure a particular concept (e.g. How can urban sustainability be measured?) and often consist of a sequence of stages with dedicated tools (Lyytimäki and Rosenström, 2008), conceptual frameworks are centered on the concept itself, along with its representation and subsequent translation into metrics (e.g. What is a sustainable city?).

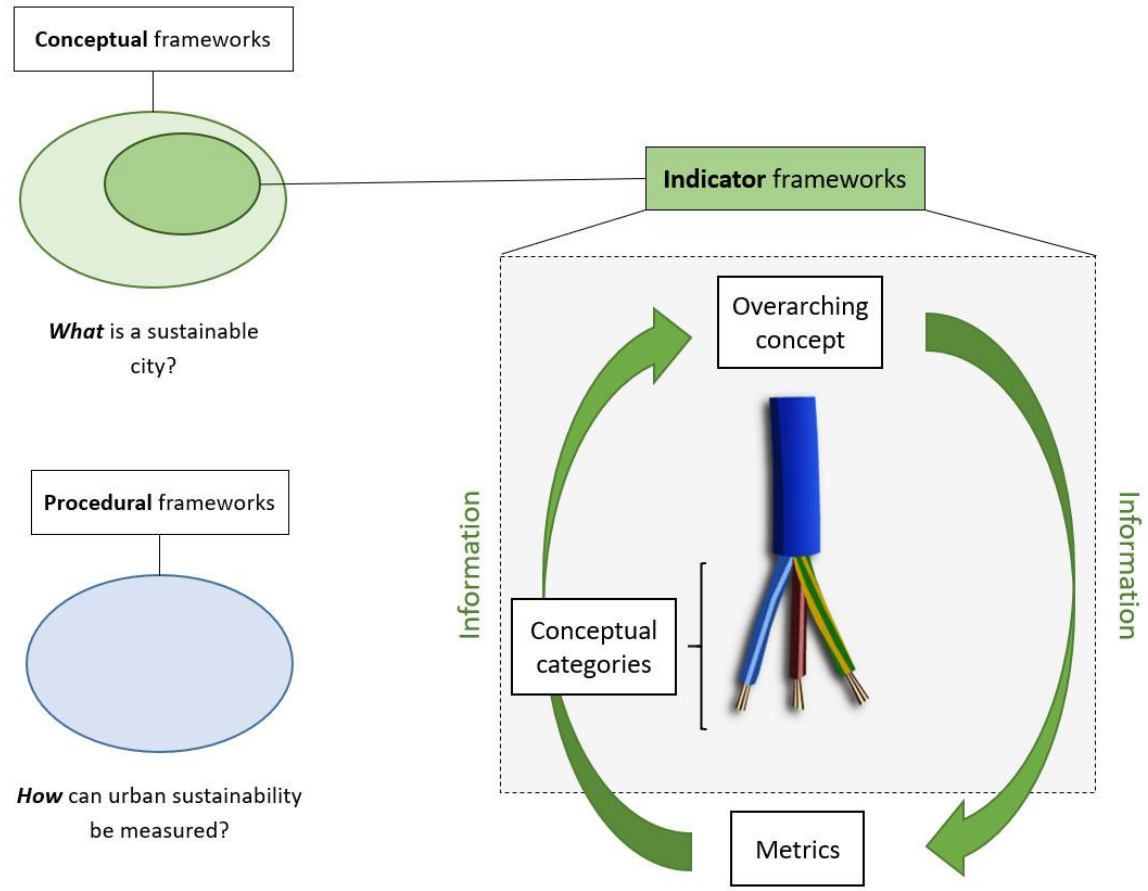

Fig. 1. Indicator frameworks as informational conductors bringing abstract concepts and tangible metrics together (source: Authors).

The focus of this study is on a particular subset of conceptual frameworks used in connection with indicators (see Fig. 1) ${ }^{1}$. Different definitions exist in the literature for such indicator frameworks, with authors understanding them as 'models' (Becker, 2005), 'structures' (Nathan and Reddy, 2012; Burgass et al., 2017) or 'networks of interrelated concepts' (Pope et al., 2017). As we understand them in this paper, indicator frameworks are made of (i) an overarching concept; (ii) a finite number of conceptual categories to which the concept at hand can be broken down; and (iii) the interlinkages between the overarching concept, the categories and related metrics. More fundamentally, indicator

\footnotetext{
${ }^{1}$ For brevity, we will henceforth refer to these kind of conceptual frameworks simply as 'indicator frameworks' or 'frameworks'.
} 
frameworks may be conceived as informational conductors through which significance flows bidirectionally between abstract concepts and tangible metrics. Understood in this way, frameworks serve several purposes (see the following section).

\subsection{What are indicator frameworks for?}

\subsection{1. (re)Defining the overarching concept to be monitored (indicator frameworks as mind maps)}

By depicting a finite set of constituent categories, indicator frameworks convey a particular understanding of the concept to be monitored (e.g. 'urban sustainability'). In that sense, indicator frameworks can be seen as mind maps, deepening the understanding of a central concept through key words and ideas. In Elgert's words, indicator frameworks crystallize per se a particular "sustainable city imaginary" (Elgert, 2018, p. 17), and as such, create a common 'meta-language' that can support interdisciplinary work and mutual learning (Sébastien and Bauler, 2013; Pope et al., 2017).

\subsubsection{Guiding indicator selection and development (indicator frameworks as radars)}

Indicator frameworks are used in indicator selection and development processes as radars through which areas that need to be covered by indicators are identified (Bossel, 1999), and as a means of spotting potential gaps and/or redundancies among the candidate indicators (Montmollin and Scheller, 2007; King, 2016). Such a scanning process allows for both the detection of possible problems of comprehensiveness and for increased parsimony (Spangenberg et al., 2002; Binder et al., 2010), thus leading towards more complete, balanced and reasonable indicator sets. The use of indicator frameworks as radars can also be done ex post, revealing degrees of coverage in existing indicator sets and allowing for comparison across several indicator initiatives (Merino-Saum et al., 2018; Feleki et al., 2018).

\subsubsection{Structuring information (indicator frameworks as skeletons)}

All sustainability indicator initiatives embed a plethora of diverse and complex information (Gallopín, 1997; Bossel, 1999). Hence, to be intelligible and meaningful, these elements need to be managed in some way. Indicator frameworks help in this task by 'organizing' (Babcicky, 2013), 'structuring' (van Oudenhoven et al., 2012), and 'classifying' (Bond et al., 2012) the information embedded in a sustainability indicator set. From this perspective, indicator frameworks can be seen as skeletons, in that they constitute the central supporting part of any indicator set without which the set would collapse into a mere conglomeration of disparate and disconnected items (Becker, 2005).

\subsubsection{Representing how a phenomenon functions (indicator frameworks as scale models)}

Indicator frameworks can be used to clarify interlinkages between both categories and indicators, and to elucidate their respective roles vis-à-vis the entire object under study (Wiek and Binder, 2005; Lewison et al., 2016). Frameworks as such not only depict what the overarching concept consists of, but can also promote a more detailed understanding of how the assessed object functions, thereby providing better insights as to how to move further towards sustainability. In this role, they can be compared with educational scale models.

\subsubsection{Putting metrics into context (indicator frameworks as anchors)}

Indicator frameworks are anchors that explicitly connect generic metrics to the concept they are expected to represent, in accordance with the object, context and general approach of the indicator initiative (Gudmundsson, 2003). In doing so, frameworks mutate otherwise non-specific metrics into 
indicators (Maggino, 2017; Merino-Saum et al., 2020) ${ }^{2}$. Indeed, by explaining how raw numbers and/or words are linked to a particular concept, indicator frameworks elucidate the concrete signification they carry in the ambit of a specific indicator set, thereby making them intelligible and relevant for decision-makers and stakeholders (Lyytimäki and Rosenström, 2008; Maggino, 2017).

\subsubsection{Communicating with the target audience (indicator frameworks as business cards)}

Finally, indicator frameworks can also be used as communication tools, summarizing key information and providing a visual identity to the indicator initiative (Gallopín, 1997; Burgass et al., 2017). From this point of view, an indicator framework can be understood as a business card comprised of text and images through which an indicator initiative is communicated to its target audience as well as demarcated from other initiatives according to its particular focus and purposes. A good illustration of this is the framework of 17 Sustainable Development Goals (SDGs), which provide a strong (visual) identity for the United Nations' Agenda 2030 (UN, 2015).

\subsection{How to develop an indicator framework?}

Generally speaking, indicator frameworks can be built from two different starting points (van ZeijlRozema et al., 2011): (i) from a specific conception of urban sustainability, which is then disaggregated into several categories (concept-driven frameworks); or (ii) from a list of key indicators considered essential and which are sequentially aggregated into progressively abstract categories (indicatordriven frameworks). In either case, the steps followed should be considered carefully and documented transparently, since it is generally a normative "process of invention, not discovery" (Turnhout, 2009, p. 404), and which significantly influences the entire indicator initiative and its potential results (Merino-Saum, 2020).

A key step in the construction process of all indicator frameworks concerns the selection of a logic according to which the internal categories of the framework are defined, with each logic leading to a distinct type of framework. A number of authors have discussed these types of indicator frameworks, both for sustainability indicators in general (Gallopín, 1997; Pintér et al., 2005; Lyytimäki and Rosenström, 2008) and, in particular, for indicators dedicated to urban sustainability (Maclaren, 1996; Olalla-Tárraga, 2006; Nathan and Reddy, 2012).

However, what is lacking in the work of the above authors - and what this article aims to achieve - is (i) a systematic empirical exploration of different categorization logics from applied indicator initiatives; (ii) a mapping of how these logics are crystallized through specific categories; and, (iii) a comparative analysis of different indicator framework types considering both their key distinctive characteristics and their respective suitability to support the purposes elaborated in Section 2.2. In the absence of such analysis, indicator set developers are missing an overview of the range of options available for framework construction, as well as an understanding of why, in certain cases, one type of framework should be preferred over another, given their different intended purposes.

\section{Materials and methods}

The methodology applied in the research followed the steps depicted in Fig. 2 . In broad terms, the methodology consisted of collecting a sample of urban sustainability indicator initiatives (Section 3.1), analyzing their respective conceptual frameworks (Sections 3.2-3.4), and creating a systematic

\footnotetext{
${ }^{2}$ We understand indicators as multifaceted constructs ideally composed of: (i) a label; (ii) a unit of measurement; (iii) a definition; (iv) accessible data; (v) a reference point; and (vi) its anchoring in a particular conceptual framework (i.e. the categories and the concept with which it is associated) (Merino-Saum et al., 2020)). This last element is what differentiates an indicator from a metric, which can be seen as a 'generic' or 'raw' indicator without any concrete meaning, thus being associable with more than one concept.
} 
comparison of the types of frameworks found in the sample (Section 3.5). The result is a typology of frameworks based on empirical evidence, with each type described by a definition and a list of typespecific categories.

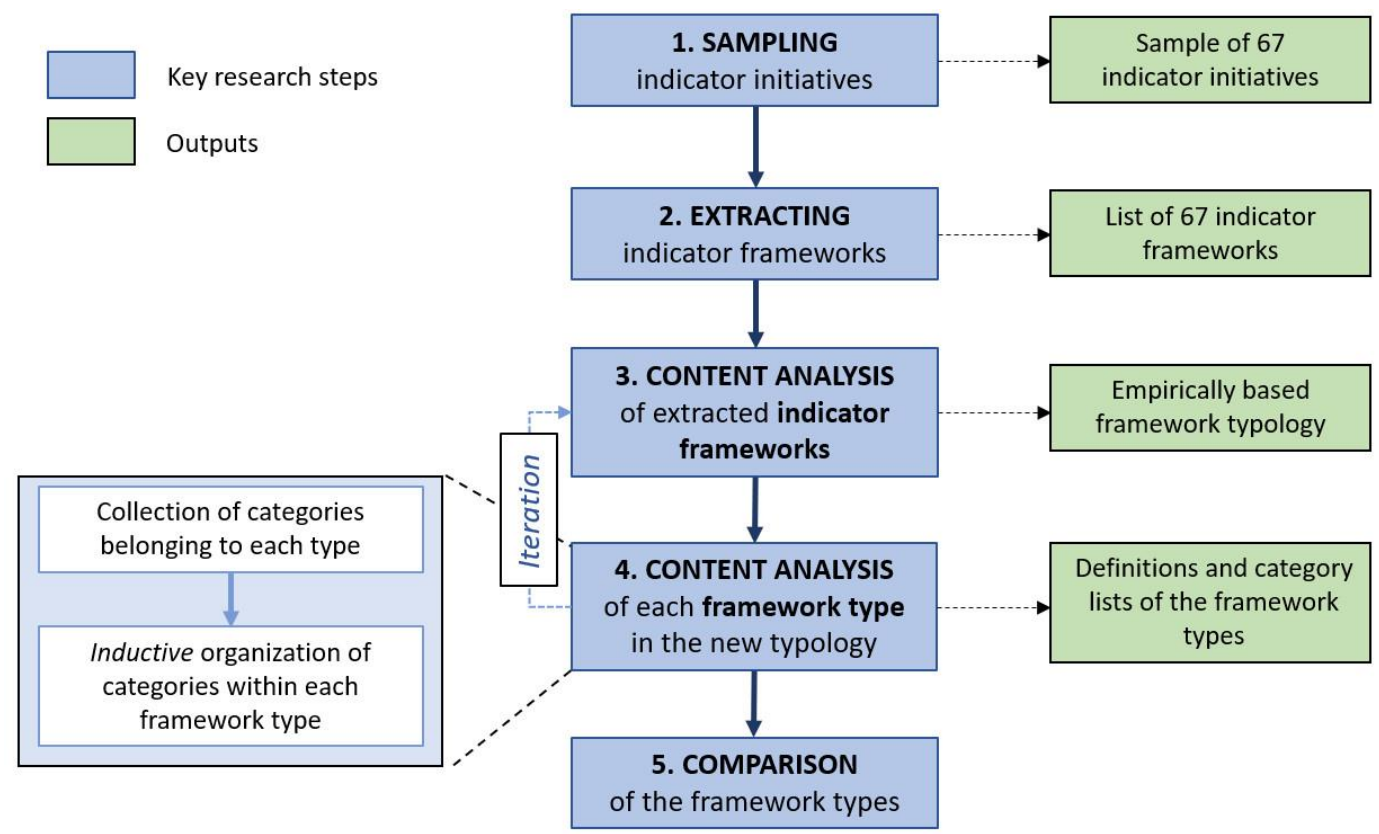

Fig. 2. The methodological steps followed in the research (source: Authors).

\subsection{Indicator initiative sampling}

The analyzed sample of indicator initiatives for urban sustainability, all developed between 2010 and 2019, was collected from both academic and grey literature (for complementary information, see: Merino-Saum et al., 2020). To create a first sample of potential indicator initiatives, the Scopus search engine was used as a means of systematically identifying relevant academic literature ${ }^{3}$. In contrast, the sampling of pertinent grey literature was more explorative: some initiatives were found through Google searches, while others were discovered by a snowball sampling method through references in related literature as well as the authors' own professional networks.

Five selection criteria were then applied to the first sample of 891 potential indicator initiatives: (i) empirical orientation; (ii) recent activity; (iii) clear and comprehensive focus on sustainability; (iv) explicit focus on the urban scale; and $(\mathrm{v})$ access to indicators. The resulting final sample contains 67 indicator initiatives, of which 30 originate from academia and 37 from public, private or non-profit entities operating at the local, regional, national or international levels (for a full list of references see supplementary material or Merino-Saum et al., 2020).

\subsection{Extracting indicator frameworks}

The second step in the methodology was extracting the indicator frameworks from the associated material (articles, reports, websites, etc., related to the indicator initiatives). All initiatives but one were found to use some type of framework. To be consistent with our definition of an indicator framework (see Fig. 1), it was necessary at this point to clearly define the cutoff line between the

\footnotetext{
${ }^{3}$ The Scopus query: KEY (indicator*) AND KEY (sustain*) AND KEY (urban) AND PUBYEAR > 2009 AND PUBYEAR < 2020 AND (LIMIT-TO (SRCTYPE, "j")) AND (LIMIT-TO (DOCTYPE, "ar")) AND (LIMIT-TO (LANGUAGE, "English") OR LIMIT-TO (LANGUAGE, "Spanish") OR LIMIT-TO (LANGUAGE, "French") OR LIMIT-TO (LANGUAGE, "Italian") OR LIMIT-TO (LANGUAGE, "German")).
} 
metrics and the framework (see Fig. 3). As a rule, to qualify as a conceptual category and therefore as part of the framework, a term had to either (i) encompass at least two more specifically defined terms (like 'Air' in Fig. 3) or (ii) belong to a group of terms existing at an equal level of specificity that generally fulfilled criterion 1 (like 'Water' as part of a group together with 'Air', 'Health' and 'Economic welfare', in Fig. 3$)^{4}$. In this manner, once the cutoff line between the metrics and the framework was determined, the terms considered to be metrics were omitted from the subsequent analysis.

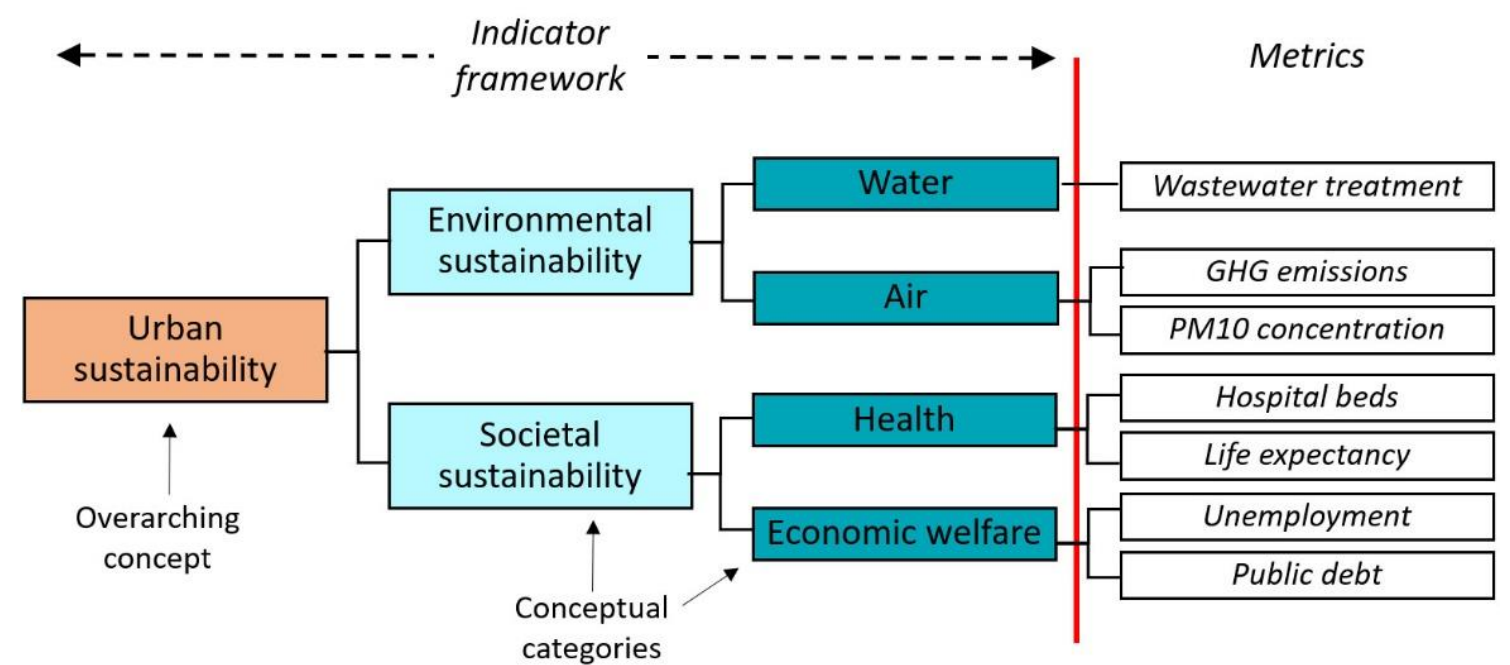

Fig. 3. An illustrative example of a distinction between conceptual categories (i.e., the indicator framework) and metrics (source: Authors).

\subsection{Content analysis of indicator frameworks}

The third step of the research process concerned a content analysis (Mayring, 2000) of the indicator frameworks extracted from the sample in order to develop a typology for their classification. More specifically, the analyzed content consisted of the titles of the conceptual categories included in the frameworks. The analysis followed an inductive procedure, whereby an initial coding scheme (representing types of categories) was first developed based on a rough scanning of the extracted frameworks. Then, a negotiated and iterative process among the authors followed, which involved assigning coding tags to the frameworks depending on the types of categories discovered within them and refining the original coding scheme to better represent the range of categories. Some frameworks in the sample were assigned a single tag (i.e., all categories representing a single type). However, in most cases the frameworks were 'hybrids' (see Section 4.1.6), i.e., they contained categories following more than one type of logic. The output of this step is a typology of indicator frameworks, where each type is defined by an archetypal logic for formulating categories of indicators of urban sustainability (See Table 1).

\subsection{Content analysis of framework types}

In the next step of the research, conceptual categories were assembled by framework type, according to the typology elaborated in the previous step. This involved the assimilation of duplicates, which considerably reduced the overall number of categories (see Fig. 4). The research team then analyzed the lists of categories in-depth with the aim of organizing them into logical structures. The analysis followed the logic of inductive content analysis (Mayring, 2000), and resulted in a distinct structure for each of the framework types (see Sections 4.1.1-4.1.5). The collection and organization of the

\footnotetext{
${ }^{4}$ The only exception to the rule was Cercle Indicateurs (2017), whose framework contains a set of items mostly encompassing one metric. However, the titles of the items are expressed in a sufficiently conceptual manner as to qualify them as conceptual categories.
} 
indicator categories within the framework types also resulted in a deeper understanding and demarcation of said types. Consequently, this led to an iterative refinement of the definitions of the framework types. To augment the transparency of the choices made in the process, lists of indicator categories considered for each of the framework types are can be found in the supplementary material.

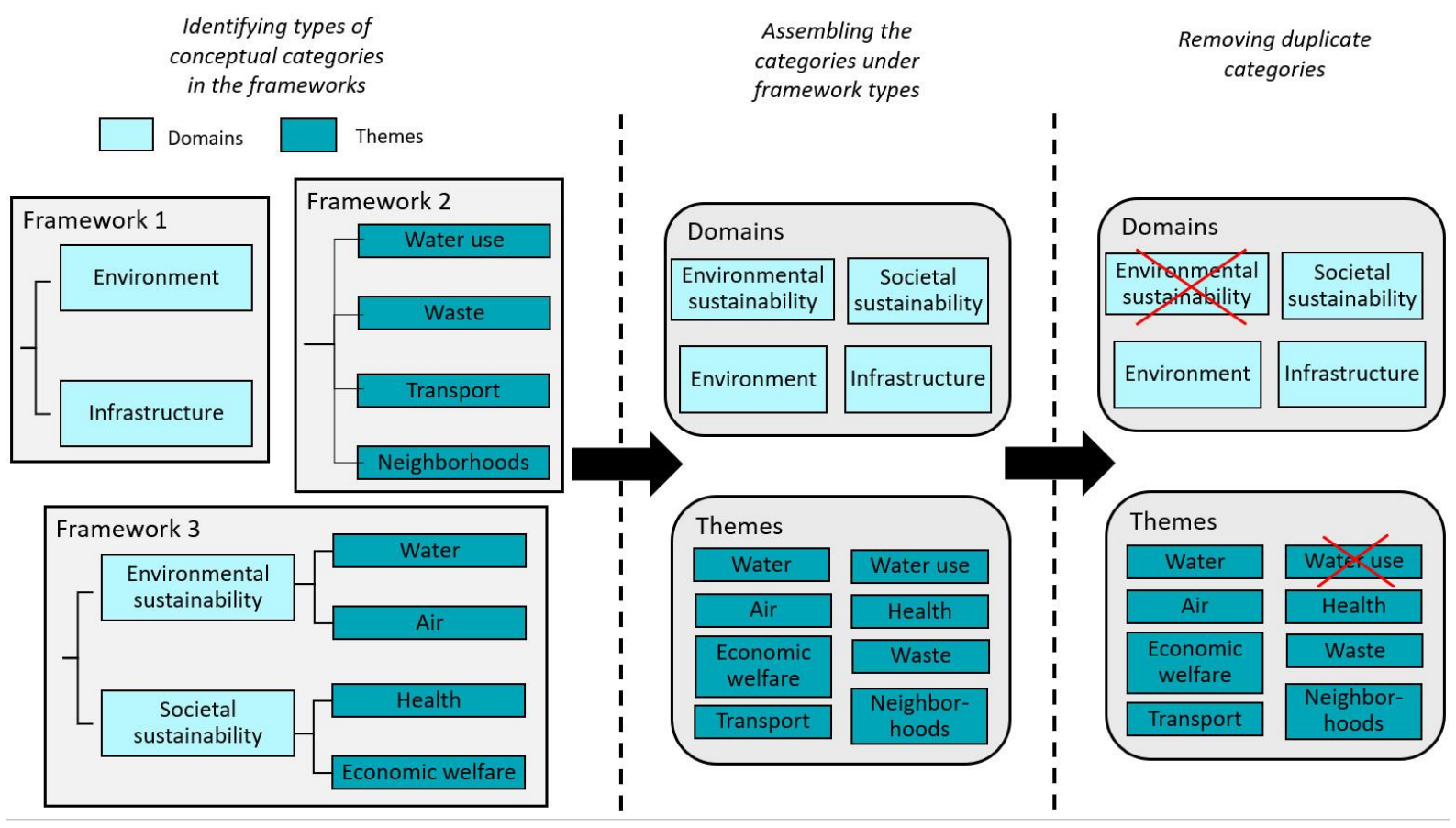

Fig. 4. An illustrative example of the collection of lists of categories for each type (source: Authors).

\subsection{Comparison of framework types}

Finally, the thorough definition and analysis of the framework types found in the sample allowed us to make comparisons between them. This comparative analysis first focused on the basic characteristics that make each framework type distinct from the others, and then, based on this, their respective suitability to address the purposes of indicator frameworks (see Section 2.2). The results of this two-step analysis are presented in Section 4.2.

\section{Results}

\subsection{New indicator framework typology for urban sustainability}

The analysis of the 67 frameworks allows us to propose the typology seen in Table 1. The typology consists of four principal types, each defined by an archetypal logic for categorizing indicators of urban sustainability. Also, a small number of frameworks in the sample displayed distinctive logics falling outside of the four principal types. These additional logics may be viewed as emerging logics in indicator framework development. In addition to the types based on a single logic, our typology also acknowledges hybrid frameworks, i.e., frameworks combining multiple logics. 


\begin{tabular}{|c|c|c|}
\hline \multicolumn{2}{|r|}{ Type } & Definition \\
\hline \multirow{4}{*}{ 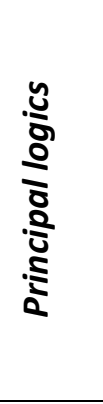 } & Domain & $\begin{array}{l}\text { Categorization based on the most general perspectives or sub-systems } \\
\text { pertinent to sustainability and reducible only to the overarching concept }\end{array}$ \\
\hline & Theme & Categorization based on topics and challenges pertinent to sustainability \\
\hline & Goal & Categorization based on outcomes seen as desirable for sustainability \\
\hline & Systemic & $\begin{array}{l}\text { Categorization based on a model that explicitly defines the relationships } \\
\text { between indicator categories }\end{array}$ \\
\hline \multirow{2}{*}{ 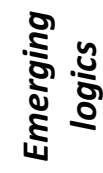 } & Spatial & Categorization based on physical location or scale \\
\hline & Epistemological & Categorization based on kinds of knowledge \\
\hline & Hybrid & $\begin{array}{l}\text { Categorization combining several of the above logics through either } \\
\text { hierarchization, juxtaposition, assimilation or matrix-like integration }\end{array}$ \\
\hline
\end{tabular}

Table 1: Typology of indicator frameworks based on the analysis of 67 urban sustainability initiatives.

\subsubsection{Domain-based frameworks}

The use of domains was prominent in the analyzed sample, with 34 out of 67 initiatives identified as using this type of logic. From the 34 frameworks, an initial list of 119 categories was produced. After the assimilation of duplicates and the removal of categories falling under the definition of other types, the final list of domain-based categories consisted of eleven examples (see Fig. 5). Among these, 'environment' ( 26 instances), 'economy' ( 24 instances) and 'society' (22 instances) were by far the most common, both in terms of their appearances individually and in combination with each other. 'Governance', on the other hand, featured only in six cases.

In addition to these four typical domains, alternative domains were also discovered. In particular, rather than a more generic 'environment', six cases used the more specific domain of 'built environment' and four cases the domain of 'natural environment'. In addition, five cases referred to 'natural resources', one of them (Xu et al., 2016) to explicitly distinguish it from 'natural environment'. Furthermore, using 'human' or 'people' as a domain instead of or alongside 'society' was preferred by some cases in the sample (Sustainable Society Foundation, 2014; Wu et al., 2018). Finally, two examples were found to use the domain of 'external connections' (Shen and Yang, 2014; Xu et al., 2016), i.e., referring explicitly to the relationship that urban systems have to their surroundings.

Note that our definition of domain-based frameworks refers to conceptions of domains as either 'perspectives' or 'sub-systems'. Indeed, both ways of understanding domains can be observed in the analyzed sample. For example, in Phillis et al. (2017) all water-related metrics are embedded within the environmental domain, thus implying that the latter is seen as a distinct sub-system. In contrast, in Smiciklas et al. (2017) water-related metrics can be found both within the economic (e.g. access to water supply) and environmental (e.g. water consumption) domains, which implies that the domains are viewed as perspectives that highlight different aspects of the theme in question. 


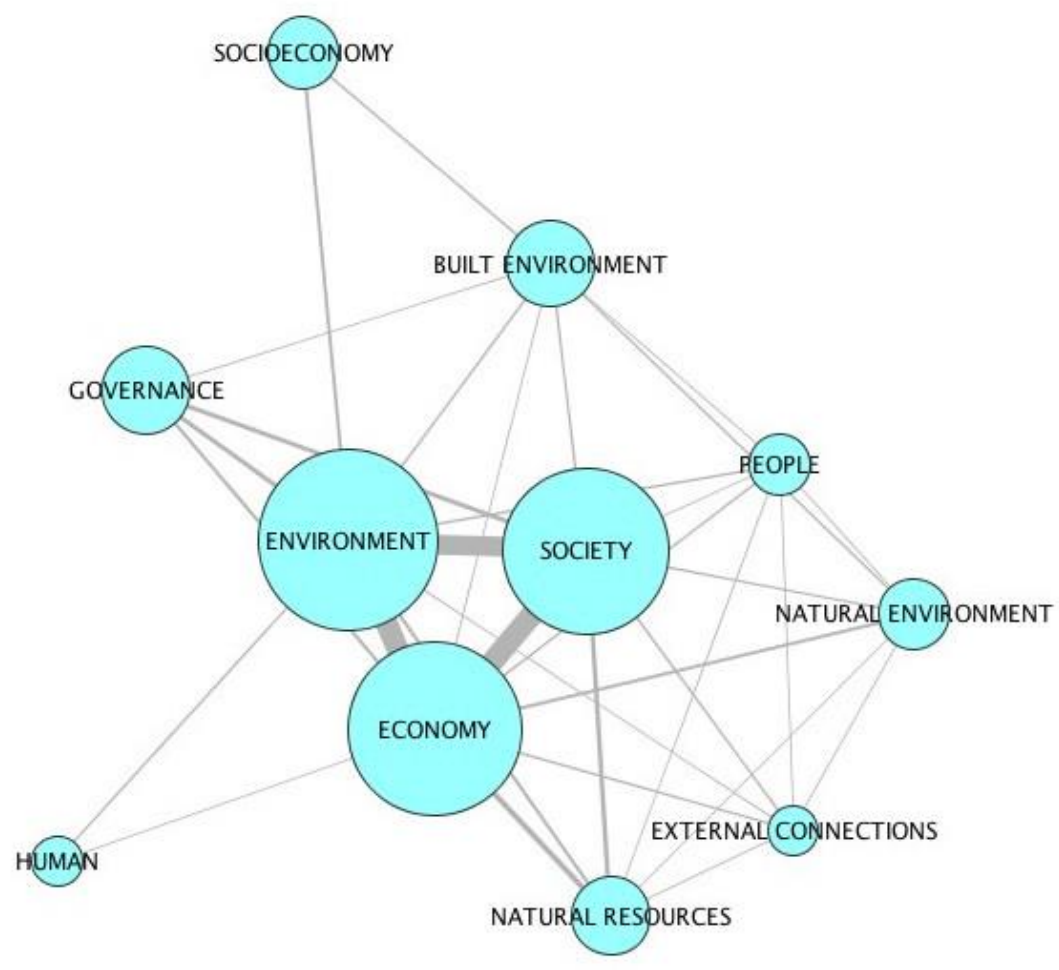

Fig. 5. The eleven domains of urban sustainability identified in the sample. The size of each node is based on the number of cases containing the respective domain. The thickness of the edges indicates the frequency with which the respective two nodes co-occur. The position of the nodes in the graph is defined using a stress minimization algorithm. The graph is drawn from data found in the supplementary material (source: Authors).

\subsubsection{Theme-based frameworks}

Themes represented the most common categorization logic of the analyzed sample, as 52 of the 67 analyzed frameworks were identified as containing categories of this type. In total, an initial list of 703 thematic categories (prior to the removal of duplicates) was collected from these frameworks. Analysis of these two categories saw the emergence of a two-tiered structure (see Table 2$)^{5}$, thus marking two subtypes of the theme-based logic. The difference between these two tiers is the specificity of the categories; the first level ('headline themes') consists of fairly general topics (e.g., transport), while the second level ('sub-themes') refers to more specific challenges (e.g., congestion). The final list of theme-based categories contains 38 headline themes and 140 sub- themes. Note that due to space restrictions Table 2 contains only a maximum of 2 sub-themes for each headline; a comprehensive list of sub-themes can be found in the supplementary material.

\footnotetext{
${ }^{5}$ Table 2 should be read as a qualitative mapping of the breadth of themes found in the sample. For quantitative information on the relative attention that the indicator sets give to different areas of sustainability, refer to Merino-Saum et al. (2020).
} 


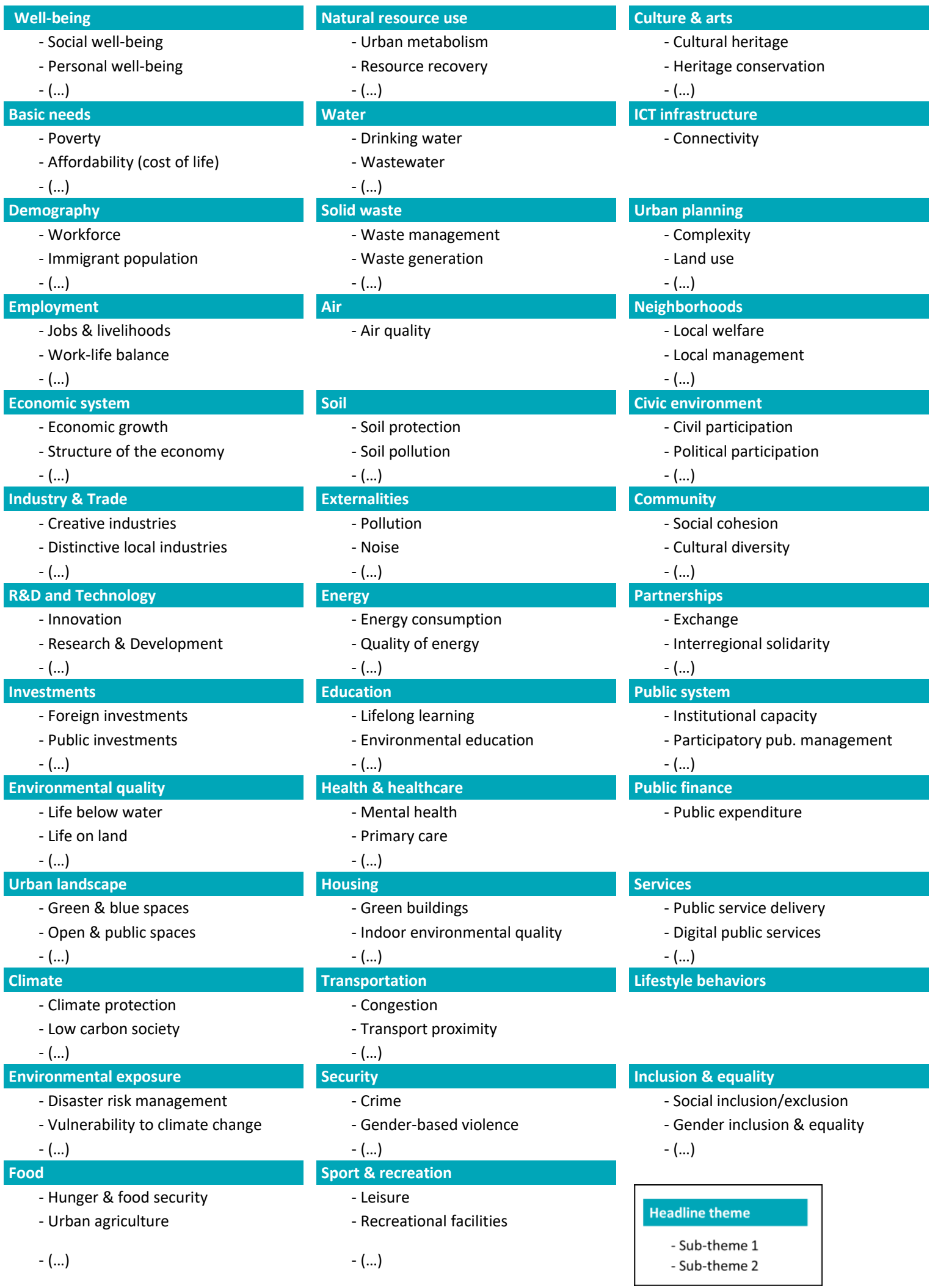

Table 2. Theme-based categories.

\subsubsection{Goal-based frameworks}

In total, 219 categories (from 18 indicator sets) were extracted with titles explicitly referring to a specific goal, i.e., an outcome seen as desirable. The analysis of these categories showed that they all 
express their respective goals by referring to a particular area of sustainability (i.e., either a domain or a theme) combined with either an action (e.g., promote, prevent), an attribute (e.g., local, healthy), or both ${ }^{6}$. From the analyzed categories, the research team identified in total a list of 20 actions, 42 attributes, and 43 areas of sustainability. The Sankey diagram presented in Fig. 6 illustrates how these actions, attributes and areas of sustainability are combined among the goal-based categories (the diagram only considers those combinations appearing more than once).

As seen in the figure, no clear trends are evident, and elements are used together in a multitude of different ways. Only a few combinations are repeatedly used in the sample, such as "assure-accessible...", "promote-sustainable-...", "reduce-externalities" or "protect-natural ecosystems". Generally speaking, goal-oriented categories are formulated in a positive manner (e.g. "promote"; "develop"; "assure"; "create"; etc.), and refer to the same domains and themes as identified in Sections 4.1.1 and 4.1.2.

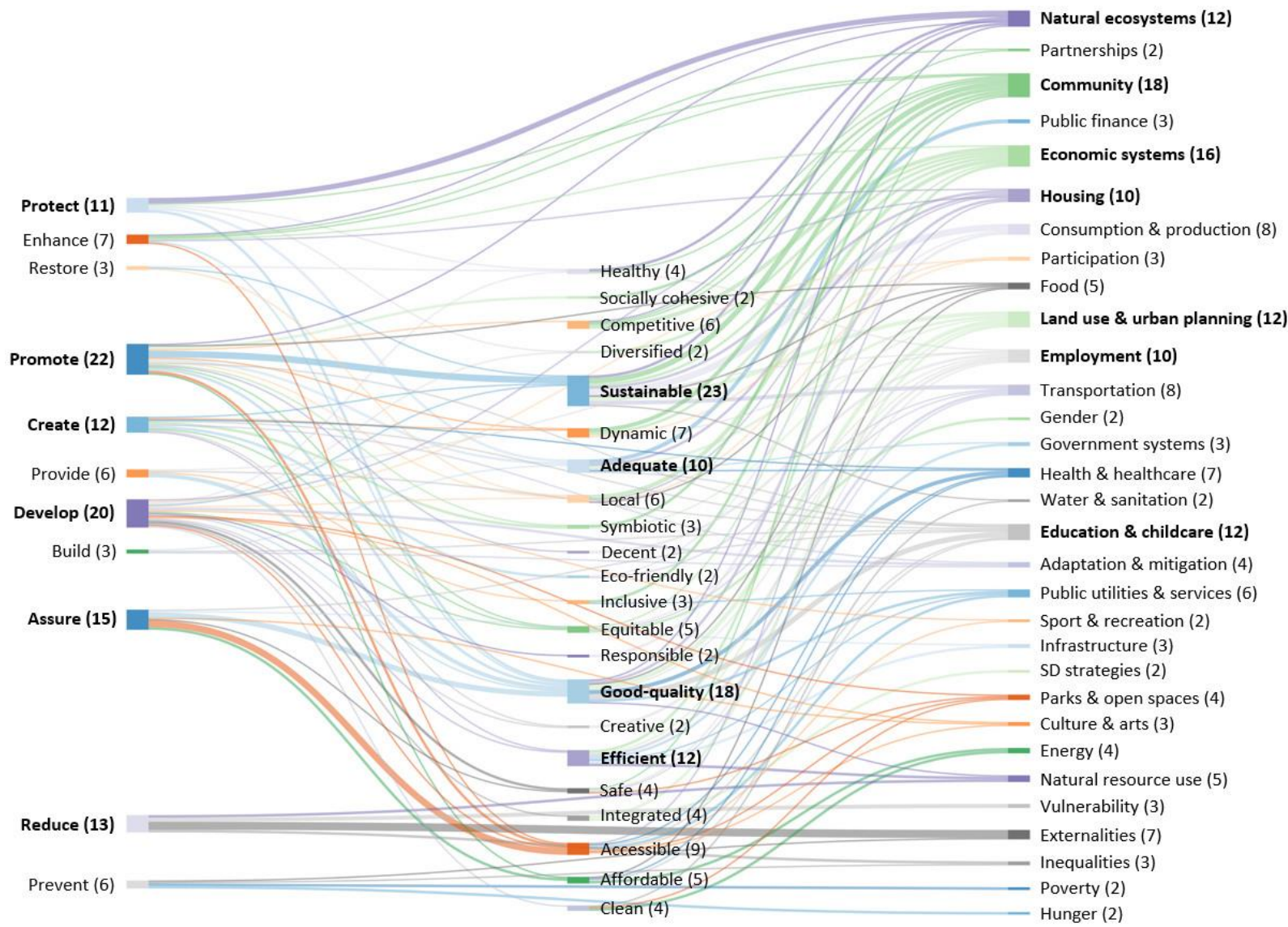

Fig. 6. Sankey diagram illustrating the diversity of goal-oriented categories found in the sample (categories are codified as combinations of actions, attributes and/or areas of sustainability). Numbers in brackets express the appearance frequency of each construct. Categories in bold appear ten times or more (source: Authors).

\subsubsection{Systemic frameworks}

In the analyzed sample, five cases were considered to fit the definition of the systemic type ${ }^{7}$. The analysis revealed that among these five cases there are two different manners of defining the relationships between categories, as illustrated by Fig. 7. Four cases (Dubiela, 2011; Wang et al., 2013;

\footnotetext{
${ }^{6} \mathrm{~A}$ theme combined with both an attribute and an action (e.g., "Promote sustainable urban transport"; "Provide good-quality housing") was the most frequent case in the sample with 85 occurrences (i.e., 38.81\%).

${ }^{7}$ To clarify, we consider two common framework models (1. A simple hierarchy of categories; 2 . A model where all categories are portrayed as connected with all other categories in a symmetric manner) to have fallen outside of the definition as insufficiently specifying the relationships between the categories.
} 
Xu et al., 2016; Valcárcel-Aguiar et al., 2019) differentiate indicator categories in terms of the functional roles that they play vis-à-vis each other within the system (Fig. 7a). In contrast, in one case (Wu et al., 2018) the relationships are elaborated via dedicated indicator categories placed at the interfaces of primary categories (Fig. 7b).

a)

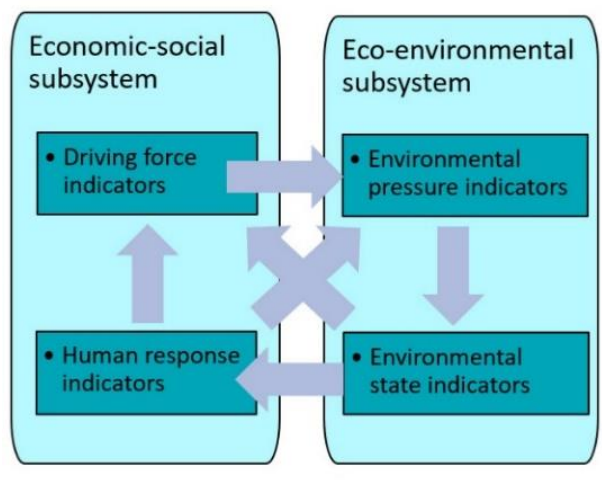

b)

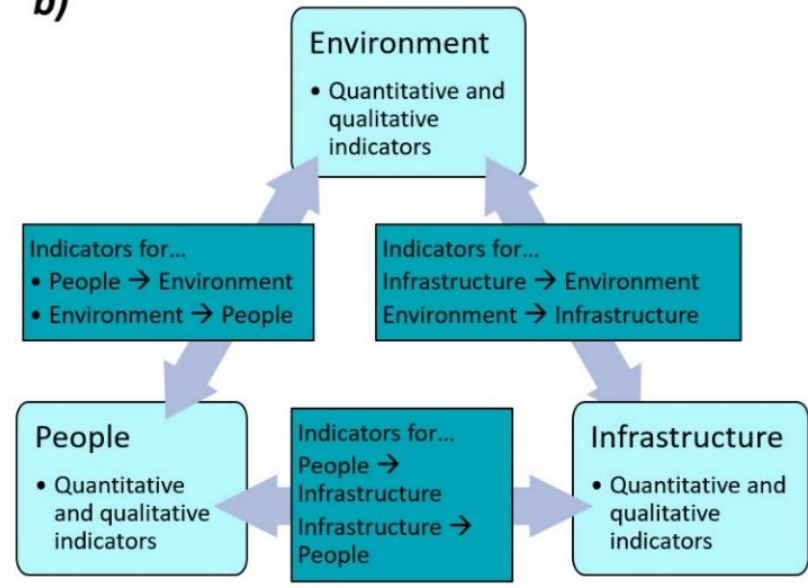

Fig. 7. Examples of systemic frameworks: a) Wang et al. (2013); b) Wu et al. (2018) (source: Authors based on said original sources).

\subsubsection{Emerging framework types}

As mentioned above, some cases in the sample were identified as using an indicator categorization logic other than the four principal types. Two such emerging logics were discovered in the sample, one making a spatial distinction between categories of indicators, and another making an epistemological distinction, i.e., categorizing indicators based on the kind of knowledge that they represent.

The spatial distinction between categories can appear in terms of scale, as in the case of Yigitcanlar et al. (2015) who identify indicators at both the micro and mezzo levels, or in the case of Balaras et al. (2019) who distinguish between building scale and neighborhood scale indicators. Alternatively, the spatial distinction can also be made in pure geographical terms. An example of the latter is Baca (2014) who discriminates between urban and rural indicators. It can be noted that several of the analyzed indicator initiatives provide measured data at different scalar levels (most often neighborhoods or districts); however, they do not conceptualize the scalar differences in their frameworks.

As for the epistemological distinction between categories of indicators, for three examples found in the sample (Baca, 2014; Wu et al., 2018; Association suisse pour des quartiers durables, 2018) this meant specifically differentiating between quantitative and qualitative indicators.

\subsubsection{Hybrid frameworks}

The framework types presented above must be understood as theoretical archetypes differentiated from each other for didactic purposes. In practice, frameworks are most often hybrids that combine several logics at once. In our sample, hybrid frameworks represent almost three quarters of the total examples (49 out of 67). Their analysis revealed four generic ways in which the hybridization occurs: (i) hierarchization; (ii) juxtaposition; (iii) assimilation; and (iv) matrix-like integration (see Fig. 8).

Hybrid frameworks most frequently rely on a hierarchical treelike structure through which categories from one type (e.g., themes) are systematically placed within one or several categories from another type (e.g., domains), as if the latter were broader constructs embedding the former. More than one third of the indicator sets in the sample are based upon such a hybrid framework, with a majority of 
them containing domains as upper-level categories and themes as lower-level ones (see for instance: (Sustainable Society Foundation, 2014; Cercle Indicateurs, 2017).

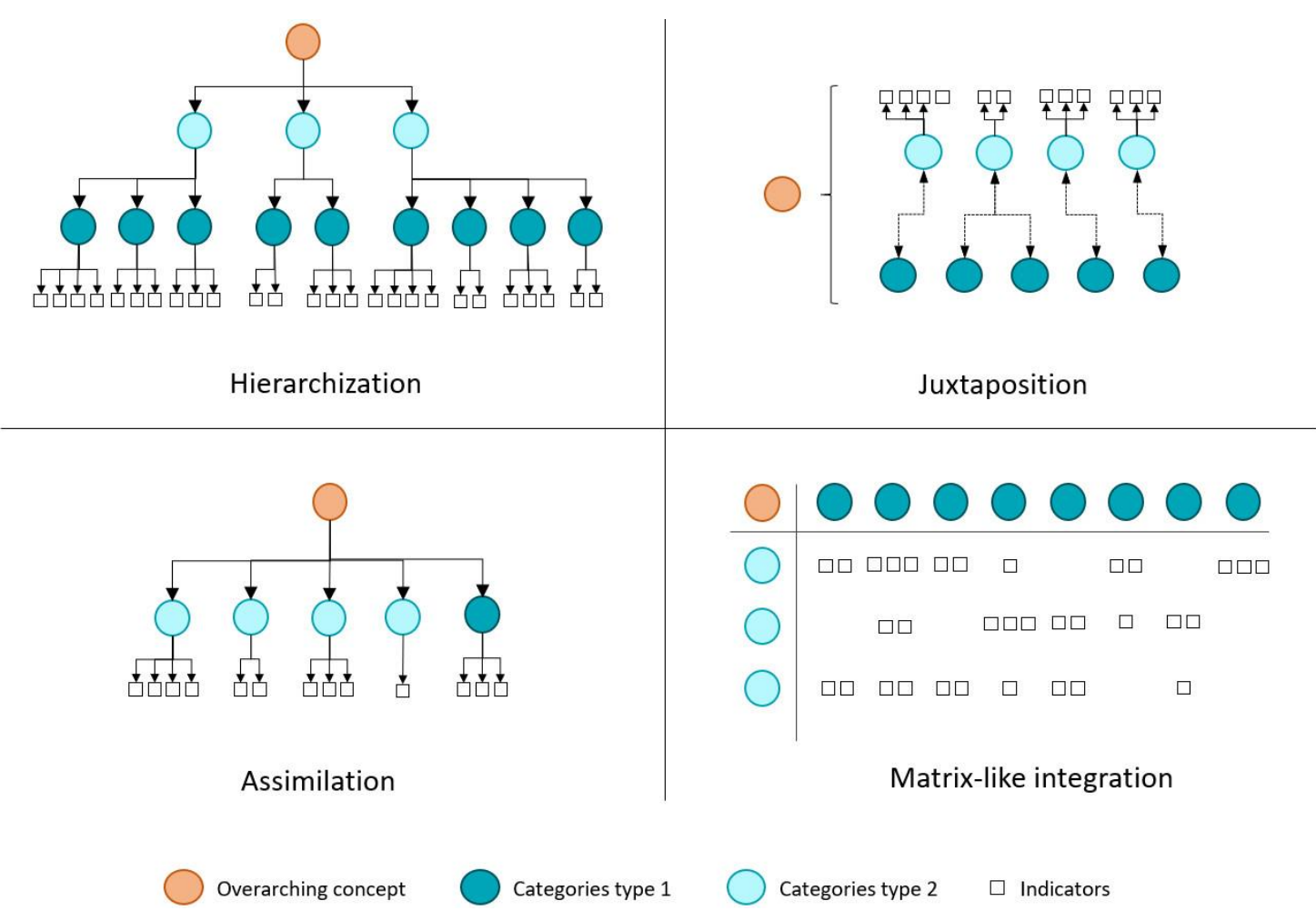

Fig. 8. A typology of hybrid frameworks observed in our sample (source: Authors).

While hierarchization involves a vertical combination of framework types, assimilation implies a horizontal one. In this manner of hybridization, categories are equated with each other without consideration of the underlying categorization logic (Keough et al., 2011; City of Minneapolis, 2012; Basque government and Udalsarea21, 2016). Assimilation most often relies on an unbalanced combination, with categories from one specific type being majoritarian and those from other types constituting isolated cases (see Fig. 8).

Hybrid frameworks can also be built by juxtaposition, where indicators are simultaneously associated with two frameworks representing two different types (generally one of them plays a central role). Most often, juxtaposition is used when co-existing frameworks fulfil different purposes within the same indicator initiative, e.g., indicator selection and communication (see Section 2.2). As an example, Smiciklas et al. (2017) connect their indicators both to a theme-based framework as well as to the framework defined by the SDGs.

Furthermore, framework types can be integrated through a matrix-like reasoning in which two different types are considered at the same descriptive level, and all categories from one type can be associated with any category from the other type. In our sample, only one indicator set relies on such a hybrid framework (Haider et al., 2018).

Finally, our analysis also demonstrates that hybrid frameworks can be built through several combinative methods. For instance, the framework of Wu et al. (2018) is framed as a tree made of two hierarchical levels: an upper one including domains and a lower one horizontally mixing themes and system components. 


\subsection{Comparison of principal framework types}

\subsubsection{Comparing the characteristics of framework types}

The analysis presented above allows us to elicit the inherent characteristics of the principal framework types with regard to each other. We make this comparison along three axes (see Fig. 9) selected to provide a maximum possible contrast between the framework types. It should be noted that the comparison refers to type-specific tendencies, and not absolutes.

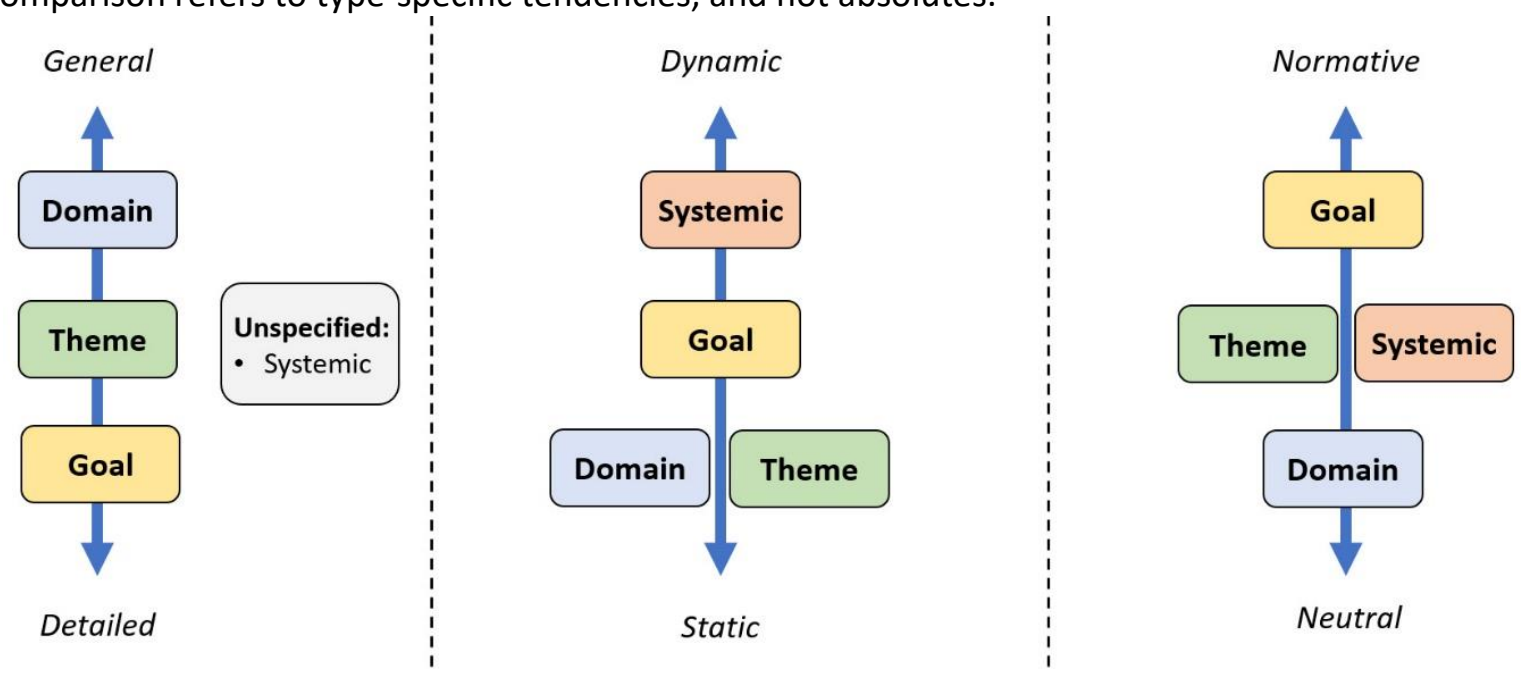

Fig. 9. Comparing the framework types (source: Authors).

The first comparative axis concerns the level of detail with which the conceptual categories are defined. Here, a progressive increase of detail can be seen proceeding first from domains (the most general type), to themes (by narrowing the focus of the categories to more specific areas of sustainability), and then to goals (by attaching actions and/or attributes to the themes). Meanwhile, the systemic type, although being more complex than the other types by including interrelationships between categories, does not inherently imply a particular level of detail.

Secondly, a difference can be made between the framework types in terms of whether they convey a predominantly dynamic or static image. Here, systemic frameworks, in attempting to capture the inner workings of the overarching concept being measured, display a dynamic understanding of said concept. At the same time, the goal-based logic, by expressing certain intended future outcomes also contains an element of dynamism. In contrast, the domain and theme types limit themselves to lists of areas of sustainability, and can therefore be described as more static than the two previous types.

Concerning the third axis of Fig. 9, goal-based logic, by explicitly specifying outcomes against which evaluations can be made, represents the highest level of normativity. However, the other logics also display varying levels of normativity. Namely, whether by adding detail (theme type) or complexity (systemic type), a framework implicitly also increases in normativity when becoming more specifically defined. Conversely, the domain type, by virtue of its generality, remains more neutral, and therefore leaves a greater part of the normative task of interpreting the meaning of the overarching concept to the selection of metrics with which the framework is populated.

\subsubsection{Comparing suitability of framework types for different purposes}

The inherent differences between the framework types presented in the previous section render them unequal in serving the different purposes elaborated in Section 2.2. For instance, given their broad level of description, domain-based frameworks might be unsuitable for deepening understanding of the overarching concept or for attributing a clear signification to related metrics. Their simplicity, 
however, makes them particularly appropriate for communication purposes. In contrast, systemic frameworks generally involve more elaborated categorizations, which certainly better explain how a particular phenomenon works, but the logics of which might be difficult to grasp for lay people, thus potentially making communication more difficult.

In Table 3, we develop this comparison of the principal framework types in more detail. Goal-oriented frameworks are seen to effectively address the highest number of different purposes (4 out of 6 ). At the same time, the systemic framework type is the only one found not to be incompatible with any of the given purposes.

\begin{tabular}{|c|c|c|c|c|}
\hline & DOMAIN-BASED & THEME-BASED & GOAL-BASED & SYSTEMIC \\
\hline 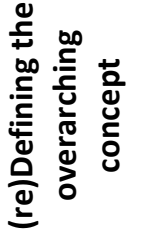 & $\begin{array}{l}\text { Remains abstract in } \\
\text { understanding of the } \\
\text { overarching concept }\end{array}$ & $\begin{array}{l}\text { By being more } \\
\text { detailed (compared to } \\
\text { domains), adding } \\
\text { clarity to concept }\end{array}$ & $\begin{array}{l}\text { More detailed than } \\
\text { either domains or } \\
\text { themes; thus, clearer in } \\
\text { understanding of } \\
\text { concept }\end{array}$ & $\begin{array}{l}\text { Contributes a } \\
\text { dynamic and holistic } \\
\text { aspect to the concept; } \\
\text { however, may remain } \\
\text { abstract }\end{array}$ \\
\hline 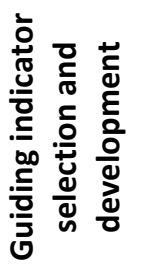 & $\begin{array}{l}\text { Helpful for easy } \\
\text { check of balance of } \\
\text { coverage; however, not } \\
\text { supportive in indicator } \\
\text { definition or selection } \\
\text { due to being unspecific }\end{array}$ & $\begin{array}{l}\text { More detailed level } \\
\text { (compared to domains) } \\
\text { assists in identifying } \\
\text { indicators; however, } \\
\text { dynamic aspects are } \\
\text { neglected }\end{array}$ & $\begin{array}{l}\text { Provides multiple } \\
\text { lenses through which } \\
\text { candidate indicators } \\
\text { can be identified (i.e., } \\
\text { themes, attributes \& } \\
\text { actions) }\end{array}$ & $\begin{array}{l}\text { By elucidating links, } \\
\text { can point to areas } \\
\text { otherwise not covered } \\
\text { by indicators; however, } \\
\text { may remain too } \\
\text { abstract or difficult }\end{array}$ \\
\hline 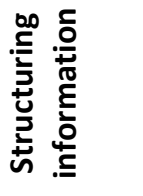 & $\begin{array}{l}\text { Not helpful due to } \\
\text { unspecific description } \\
\text { of categories }\end{array}$ & $\begin{array}{l}\text { The specificity of } \\
\text { categories facilitates } \\
\text { easier organization of } \\
\text { information }\end{array}$ & $\begin{array}{l}\text { High potential by } \\
\text { having highly specific } \\
\text { categories (actions, } \\
\text { attributes and themes) }\end{array}$ & $\begin{array}{l}\text { May remain too } \\
\text { abstract or complex for } \\
\text { this purpose }\end{array}$ \\
\hline 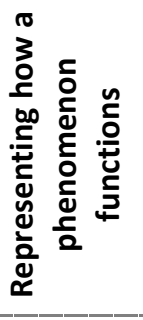 & $\begin{array}{l}\text { Says very little, if } \\
\text { anything, about the } \\
\text { functioning of a } \\
\text { phenomenon }\end{array}$ & $\begin{array}{l}\text { Says very little, if } \\
\text { anything, about the } \\
\text { functioning of a } \\
\text { phenomenon }\end{array}$ & $\begin{array}{l}\text { Despite involving a } \\
\text { certain dynamic } \\
\text { perspective, saying } \\
\text { little about the } \\
\text { functioning of a } \\
\text { phenomenon }\end{array}$ & $\begin{array}{l}\text { By elucidating both } \\
\text { links between } \\
\text { components and their } \\
\text { respective functions, } \\
\text { particularly well-suited } \\
\text { for this purpose }\end{array}$ \\
\hline 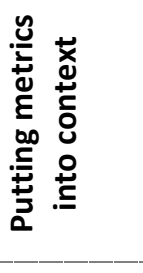 & $\begin{array}{l}\text { Not much support } \\
\text { for anchoring metrics } \\
\text { due to low level of } \\
\text { detail }\end{array}$ & $\begin{array}{l}\text { Connecting metrics } \\
\text { to themes generally } \\
\text { elucidates a precise } \\
\text { anchor }\end{array}$ & $\begin{array}{l}\text { With the presence of } \\
\text { specific goals is able to } \\
\text { confer a precise } \\
\text { anchoring to any metric }\end{array}$ & $\begin{array}{l}\text { Can provide a very } \\
\text { specific anchoring to } \\
\text { metrics; however, may } \\
\text { be too abstract or } \\
\text { complex for anchoring } \\
\text { metrics understandably }\end{array}$ \\
\hline 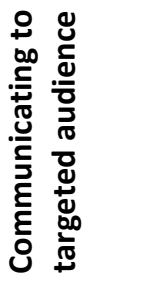 & $\begin{array}{l}\text { Easy to understand } \\
\text { and resonates with } \\
\text { all audiences; however, } \\
\text { meaning may be } \\
\text { ambiguous due to lack } \\
\text { of specificity }\end{array}$ & $\begin{array}{l}\text { Generally easy to } \\
\text { understand and } \\
\text { relatable to a wide } \\
\text { audience }\end{array}$ & $\begin{array}{l}\text { Generally easy to } \\
\text { understand and } \\
\text { relatable to a wide } \\
\text { audience; however, } \\
\text { normativity may make } \\
\text { acceptance more } \\
\text { difficult }\end{array}$ & $\begin{array}{l}\text { Limited under- } \\
\text { standability and } \\
\text { resonance with non- } \\
\text { experts; some systemic } \\
\text { frameworks known in } \\
\text { the policy arena (e.g. } \\
\text { PSR, DPSIR) }\end{array}$ \\
\hline
\end{tabular}

Table 3. Comparing principal framework types across purposes. The color scheme indicates the suitability of the type for the given purpose (red = poor; yellow = ambiguous; green = good), with the type considered best indicated by the grey background color of the cell. 


\section{Discussion}

\subsection{The new indicator framework typology}

As we have argued, conceptual frameworks constitute a central component in the translation of the concept of urban sustainability into sets of indicators. This claim is supported by the observation that 66 of the analyzed 67 urban indicator initiatives employed a conceptual framework of some kind. To support the design of these frameworks, the analysis presented in the preceding results sections elucidates a typology that aims to make explicit the available options, both in terms of types of frameworks and their internal categories.

The typology, which consists of four principal and two emerging types, can be contrasted with earlier scholarly work on urban indicator frameworks, especially Maclaren (1996), Olalla-Tárraga (2006) and Nathan and Reddy (2012). When compared with these authors, our typology represents both an elaboration and a simplification. In terms of the elaboration, the work presented in this paper deepens our knowledge of the four principal framework types (domain, theme, goal and systemic) in several ways: first, by giving each type a clear definition that demarcates them from each other, thereby furnishing them with a more precise meaning; second, by elaborating on their internal structure and sub-types; third, by making explicit the features that differentiate them from each other; fourth, by illustrating a list of potential categories for each type. Furthermore, our analysis revealed two emerging framework types (spatial and epistemological) not mentioned by the above authors. Although these types of frameworks were exceptions in the analyzed sample, they nevertheless represent interesting alternatives to the more established framework types.

In terms of simplification, the typology collates three types discussed by the previous authors ('sectoral', 'issue-based' and 'thematic') into one 'theme-based' type, because any difference between the three logics is, in practice, difficult to maintain. At the same time, we illustrate that the themebased logic is not monolithic, but can be made operational at different descriptive levels (see Table 2). In addition, our typology makes an association between several types discussed by the above authors ('causal', 'capital', 'ecosystemic', 'systems') based on the observation that all of these types share a common focus on the interrelationships between categories, thus warranting the creation of a general 'systemic' type.

The methodical analysis of the framework types also allows us to draw conclusions with regard to their relative suitability to serve different purposes (see Table 3). As we show, none of the types presented in this paper are able to perfectly address all of the potential indicator framework roles (i.e., frameworks as mind maps, radars, skeletons, scale models, anchors and/or business cards; see section 2.2). Hence, the selection of a framework type should hinge on the particular aims, context and target audience of each indicator initiative. For example, while supporting communication can be a key priority when the initiative is primarily addressed to the general public, representing how a system functions likely has greater resonance in scientific contexts.

\subsection{The meaning ascribed by the indicator frameworks to 'urban sustainability'}

Another aim of the present paper was to inquire into what is included and excluded in the indicator frameworks, and in doing so contribute to a discussion about the meaning of the concept of urban sustainability. The first relevant observation is the pure number of cases using a particular logic for framework construction: out of the 67 cases analyzed, 52 used theme-based logic, 34 domain-based logic, 18 goal-based logic and 5 systemic logic. This implies that, at least at the framework level, urban sustainability is mostly conceptualized as a matter of different areas (domains, themes) of concern, and less so as an explicitly value-laden concept related to specific normative goals (Wiek and Binder, 2005). The low number of frameworks utilizing a systemic framing also conveys an impression of urban 
sustainability mostly understood as being composed of discrete and static rather than interconnected and dynamic elements. Arguably, such framing of the concept is rather simplistic, and is only partly compensated by the added conceptual depth gained through the use of multi-tiered hybrid frameworks.

The analysis of the domain-based categories revealed that the standard three pillar model (environment, society, economy) continues to be an influential vision for urban sustainability. However, our mapping also uncovered other possible domains that project a more nuanced meaning behind urban sustainability. For example, by distinguishing the domain of built environment from natural environment, some of the analyzed frameworks highlight that the presence of human-made infrastructures is a distinct, even definitional characteristic of cities (UN, 2019). Likewise, separating the domain of natural resources from natural environment, as some of the analyzed frameworks do, emphasizes the reliance of cities on their hinterlands for resource inputs (Rees and Wackernagel, 1996), and more generally highlights two distinct conceptions of the relationship between humans and nature (ecocentric vs. anthropocentric).

The great number of thematic categories (Table 2) evidenced by our analysis paints urban sustainability as encompassing a broad variety of subjects, focuses and concerns. In fact, this multiplicity can be argued to represent a distinct feature of both urban systems and urban sustainability (Halla et al., 2020), reflecting the role of cities as hubs of people, infrastructures and socioeconomic activity (Mori and Christodoulou, 2012). Indeed, disregarding this multiplicity, and evaluating the sustainability of cities for example only on their environmental records would mean ignoring the leading role that cities play in the socioeconomic aspects of sustainability.

The important relationship between cities and their surroundings (locally or globally) is generally poorly represented in the frameworks of the sample, with only a few exceptions explicitly referring to the topic (Baca, 2014; Shen and Yang, 2014; Xu et al., 2016). This can be considered a crucial omission, as managing the leakage effects of urban systems constitutes a central challenge in urban sustainability (Kennedy et al., 2007). Another feature of urban sustainability found absent in the frameworks concerns the temporal dimension. This aspect could be taken into account, for example, by categories referring to different time horizons (e.g., 'now' and 'later' in UN (2014); 'immediate', 'medium-term' and 'long term' in Alderton et al. (2019)).

In summary, the analyzed sample displays a broad diversity of interpretations of urban sustainability, both in terms of the level of detail embedded in the frameworks (ranging from a few domains to complex systemic framings), as well as the selected categories (ranging from the standard three pillars of sustainability to categories tailored to the urban context). To some extent, the frameworks can be criticized for their simplicity (e.g., the low number of systemic frameworks) or for neglecting certain key areas of urban sustainability (e.g., spatial and temporal aspects). Of course, any criticism of the conceptual shortcomings of the indicator frameworks must be tempered given that generally they must, in contrast to those conceptual frameworks expressly developed to support scientific analysis (e.g., Ramaswami et al., 2012), reconcile accuracy with the requirement of understandability among non-expert stakeholders.

\subsection{Recommendations to indicator set developers}

Based on the analysis presented above, we put forward the following recommendations for future urban indicator set developers. The first recommendation is simply to grant adequate attention to tailoring a framework that is suitable for the context-dependent needs of the indicator initiative, since it directly influences how compelling the initiative as a whole will be. In particular, this tailoring pertains to the selection of a particular categorization logic (domain, theme, goal, systemic, etc.) based on which the indicator framework is constructed, since each type of logic has its own strengths and 
weaknesses in serving different purposes. In addition, populating the framework with a list of categories should reflect the specific characteristics of the object being measured (e.g., a particular city with specific challenges), and not merely follow the blueprints of earlier initiatives.

The second recommendation relates to the level of elaboration incorporated into the indicator framework. This decision involves a tradeoff. On the one hand, a highly elaborated framework can ensure a more detailed coverage of pertinent areas and goals of sustainability, as well as provide functional information about the system being measured, thereby better enabling the design and monitoring of different intervention strategies. On the other hand, frameworks which are too convoluted can become limited in practical applicability and understandability. Therefore, we recommend that the level of elaboration of the framework is addressed explicitly at an early stage of the development of an indicator initiative. The decision should hinge on the purposes targeted by the initiative in question; in particular, whether the aims of the initiative relate more to communication or to the production of scientific knowledge. It is also perfectly possible to use two parallel frameworks, with one used for communication and another for scientific purposes.

Third, to target several purposes simultaneously, hybrid solutions combining elements from several types can be recommended. In such cases, set developers must carefully consider potential problems of coherence. Notably, particular caution should be exercised when categories based on different logics are assimilated to each other (see Fig. 8). For example, considering categories that express a different level of detail as equivalent (e.g., assimilating the domain 'society' and the theme 'waste management') creates an imbalance in the framework whereby some aspects of urban sustainability receive disproportionate attention in comparison with others. Another form of imbalance is created if normative goal-based categories are mixed with purely descriptive ones (e.g., 'efficient economy' vs. 'society').

The fourth recommendation concerns the use of domains in indicator framework construction. Despite its ubiquity, the meaning of the concept of domain is not obvious, as it can be understood as either a sub-system or as a perspective (see Section 4.1.1 and Purvis et al., 2019). This alters the meaning of each domain category, and consequently also changes the group of metrics which should be selected for each category. Therefore, to avoid confusion and randomness in choosing which metrics are to be contained within each domain, the recommendation is to clearly define what the domains represent in each application.

Finally, as outlined throughout the analysis and discussion in this paper, urban sustainability can be expressed through a multiplicity of possible frameworks, and the decisions taken to arrive at a particular framing have normative consequences. Therefore, if the ambition is to develop an indicator set through an inclusive procedure involving both experts and non-expert stakeholders, the inclusiveness should also extend to the phase of framework development. This not only enhances the ability of the resulting indicator set to adequately capture the diversity of concerns embedded in the concept of sustainability, but it also allows for the involved actors to discursively develop a common understanding of what a sustainable city is.

\section{Conclusion}

Conceptual frameworks are a central but often unappreciated part of indicator initiatives, despite the many important roles that they may perform, and the normative power they wield. The work reported in this article contributes to making the development of these frameworks more reflective and transparent. We achieve this by creating a typology of frameworks based on a comprehensive empirical sample, by discussing the relative strengths and weaknesses of each framework type, and by highlighting the gaps that remain in the conceptualizations used by current indicator initiatives. Through the analysis, the presentation of available options (both in terms of types of frameworks and 
their internal categories), and the general recommendations that we formulate, we hope to assist indicator set developers in formulating frameworks that are appropriate for their particular purposes. In general, we hope that this contribution lends attention and encourages debates on this specific yet crucial aspect of (urban) sustainability assessment.

The analysis of a large number of indicator frameworks presented in this article also provides an interesting overview of the practical meaning of the concept of urban sustainability. Knowledge on this is crucial, given the influence that such framing exerts in the shaping of ensuing actions and policies. The analysis revealed a generally multifaceted understanding of urban sustainability in terms of breadth of areas covered. However, important omissions remain, especially related to spatial and temporal aspects of urban sustainability, and to the creation of more complex, systemic conceptualizations of the concept. Filling these gaps in upcoming indicator initiatives constitutes a major opportunity to better orientate decision-making processes towards more sustainable cities.

\section{Acknowledgements}

We gratefully acknowledge Dr. Livia Fritz, Dr. Silvia Hostettler and Prof. Dr. Claudia R. Binder for their comments on a previous version of this paper, as well as Dr. Romano Wyss for drawing Fig. 5. Authors acknowledge support from Swiss Mobiliar (536527) as part of the funding of the Laboratory for Human Environment Relations in Urban Systems (HERUS) at EPFL. The research and preparation of the article was conducted without the involvement of the funding sources.

\section{References}

Alderton, A., Davern, M., Nitvimol, K., Butterworth, I., Higgs, C., Ryan, E., Badland, H., 2019. What is the meaning of urban liveability for a city in a low-to-middle-income country? Contextualising liveability for Bangkok, Thailand. Glob. Health 15, 51. https://doi.org/10.1186/s12992-0190484-8

Association suisse pour des quartiers durables, 2018. Plan d'Action de Durabilité OPL: Objectifs chiffrés de performances - Modèle générique pour la Suisse. Retrieved from https://oneplanetliving.ch/wp-content/uploads/2019/03/OPL-OBJECTIFS-Suisse-.pdf

Babcicky, P., 2013. Rethinking the Foundations of Sustainability Measurement: The Limitations of the Environmental Sustainability Index (ESI). Soc. Indic. Res. 113, 133-157. https://doi.org/10.1007/s11205-012-0086-9

Baca, J.C., 2014. Distrito metropolitano de Quito secretaría de ambiente. Indicadores de Ciudad Sostenible. City of Quito, Distrito metropolitano de Quito secretaría de ambiente. Retrieved from http://www.quitoambiente.gob.ec/

Balaras, C.A., Droutsa, K.G., Dascalaki, E.G., Kontoyiannidis, S., Moro, A., Bazzan, E., 2019. Urban Sustainability Audits and Ratings of the Built Environment. Energies 12, 4243. https://doi.org/10.3390/en12224243

Basque government, Udalsarea21, 2016. V Report on the Local Sustainability of the Basque Country. Ihobe, Ministry for the Environment and Territorial Planning, Basque Government.

Becker, J., 2005. Measuring progress towards sustainable development: an ecological framework for selecting indicators. Local Environ. 10, 87-101. https://doi.org/10.1080/1354983042000309333 
Binder, C.R., Feola, G., Steinberger, J.K., 2010. Considering the normative, systemic and procedural dimensions in indicator-based sustainability assessments in agriculture. Environ. Impact Assess. Rev. 30, 71-81. https://doi.org/10.1016/j.eiar.2009.06.002

Bond, A., Morrison-Saunders, A., Pope, J., 2012. Sustainability assessment: the state of the art. Impact Assess. Proj. Apprais. 30, 53-62. https://doi.org/10.1080/14615517.2012.661974

Bossel, H., 1999. Indicators for sustainable development. International Institute for Sustainable Development, Winnipeg, Man.

Burgass, M.J., Halpern, B.S., Nicholson, E., Milner-Gulland, E.J., 2017. Navigating uncertainty in environmental composite indicators. Ecol. Indic. 75, 268-278. https://doi.org/10.1016/j.ecolind.2016.12.034

Cercle Indicateurs, 2017. Fiches d'indicateurs Villes 2017. Retrieved from https://www.bfs.admin.ch/bfs/fr/home/statistiques/developpement-durable/cercleindicateurs.assetdetail.10227827.html

City of Minneapolis, 2012. Sustainability report. Minneapolis City Coordinator - Sustainability Office.

Dubiela, V., 2011. Indicateurs de durabilité urbaine selon une approche épidémiologique : la ville de Maringá, au Brésil. Université de Montréal, Montréal. Retrieved from https://papyrus.bib.umontreal.ca/xmlui/handle/1866/5138

Elgert, L., 2018. Rating the sustainable city: 'Measurementality', transparency, and unexpected outcomes at the knowledge-policy interface. Environ. Sci. Policy 79, 16-24. https://doi.org/10.1016/j.envsci.2017.10.006

Feleki, E., Vlachokostas, C., Moussiopoulos, N., 2018. Characterisation of sustainability in urban areas: An analysis of assessment tools with emphasis on European cities. Sustain. Cities Soc. 43, 563577. https://doi.org/10.1016/j.scs.2018.08.025

Gallopín, G.C., 1997. Indicators and Their Use: Information for Decision-Making, in: Moldan, B., Billharz, S. (Eds.), Sustainability Indicators. Report of the Project on Indicators of Sustainable Development, Scientific Committee on Problems of the Environment (SCOPE). Wiley, Chichester, pp. 13-27.

Gudmundsson, H., 2003. The Policy Use of Environmental Indicators - Learning from Evaluation Research. J. Transdiscipl. Environ. Stud. 2, 1-12.

Haider, H., Hewage, K., Umer, A., Ruparathna, R., Chhipi-Shrestha, G., Culver, K., Holland, M., Kay, J., Sadiq, R., 2018. Sustainability assessment framework for small-sized urban neighbourhoods: An application of fuzzy synthetic evaluation. Sustain. Cities Soc. 36, 21-32. https://doi.org/10.1016/j.scs.2017.09.031

Hák, T., Janoušková, S., Moldan, B., 2016. Sustainable Development Goals: A need for relevant indicators. Ecol. Indic. 60, 565-573. https://doi.org/10.1016/j.ecolind.2015.08.003

Halla, P., Wyss, R., Binder, C.R., 2020. Conceptualizing Urban Systems for Sustainability Assessment: Four Powerful Metaphors, in: Binder, C.R., Wyss, R., Massaro, E. (Eds.), Sustainability Assessment of Urban Systems. Cambridge University Press, Cambridge, pp. 241-260.

IPCC, 2014. Climate Change 2014: Mitigation of Climate Change. Working Group III Contribution to the IPCC Fifth Assessment Report. Cambridge University Press, Cambridge and New York. 
Kennedy, C., Cuddihy, J., Engel-Yan, J., 2007. The Changing Metabolism of Cities. J. Ind. Ecol. 11, 4359. https://doi.org/10.1162/jie.2007.1107

Keough, N., Morrison, B., Verwijs, H., Parker, R., Einseidel, B., Turner, C., Macaulay, C., 2011. Sustainable Calgary state of our city report. Sustainability in a generation. Sustainable Calgary. Retrieved from http://www.sustainablecalgary.org/publications-1/2018/3/25/state-of-ourcity-2011

King, L.O., 2016. Functional sustainability indicators. Ecol. Indic. 66, 121-131. https://doi.org/10.1016/j.ecolind.2016.01.027

Lewison, R.L., Rudd, M.A., Al-Hayek, W., Baldwin, C., Beger, M., Lieske, S.N., Jones, C., Satumanatpan, S., Junchompoo, C., Hines, E., 2016. How the DPSIR framework can be used for structuring problems and facilitating empirical research in coastal systems. Environ. Sci. Policy 56, 110119. https://doi.org/10.1016/j.envsci.2015.11.001

Lyytimäki, J., Rosenström, U., 2008. Skeletons out of the closet: effectiveness of conceptual frameworks for communicating sustainable development indicators. Sustain. Dev. 16, 301313. https://doi.org/10.1002/sd.330

Maclaren, V.W., 1996. Urban Sustainability Reporting. J. Am. Plann. Assoc. 62, 184-202. https://doi.org/10.1080/01944369608975684

Maggino, F. (Ed.), 2017. Complexity in Society: From Indicators Construction to their Synthesis, Social Indicators Research Series. Springer International Publishing, Cham. https://doi.org/10.1007/978-3-319-60595-1

Mayring, P., 2000. Qualitative Content Analysis. Forum Qual. Sozialforschung Forum Qual. Soc. Res. 1. https://doi.org/10.17169/fqs-1.2.1089

Merino-Saum, A., 2020. Assessing Urban Sustainability through Participatory Multi-Criteria Approaches (PMCAs): An Updated Comparative Analysis, in: Binder, C.R., Wyss, R., Massaro, E. (Eds.), Sustainability Assessment of Urban Systems. Cambridge University Press, Cambridge, pp. 209-237.

Merino-Saum, A., Baldi, M.G., Gunderson, I., Oberle, B., 2018. Articulating natural resources and sustainable development goals through green economy indicators: A systematic analysis. Resour. Conserv. Recycl. 139, 90-103. https://doi.org/10.1016/j.resconrec.2018.07.007

Merino-Saum, A., Halla, P., Superti, V., Boesch, A., Binder, C.R., 2020. Indicators for urban sustainability: Key lessons from a systematic analysis of 67 measurement initiatives. Ecol. Indic. 119, 106879. https://doi.org/10.1016/j.ecolind.2020.106879

Miles, M.B., Huberman, A.M., Saldaña, J., 2014. Qualitative data analysis: a methods sourcebook, Third edition. ed. SAGE Publications, Inc, Thousand Oaks, Califorinia.

Montmollin, A.D., Scheller, A., 2007. MONET indicator system: the Swiss road to measuring sustainable development. Int. J. Sustain. Dev. 10, 61. https://doi.org/10.1504/IJSD.2007.014414

Mori, K., Christodoulou, A., 2012. Review of sustainability indices and indicators: Towards a new City Sustainability Index (CSI). Environ. Impact Assess. Rev. 32, 94-106. https://doi.org/10.1016/j.eiar.2011.06.001 
Munier, N., 2011. Methodology to select a set of urban sustainability indicators to measure the state of the city, and performance assessment. Ecol. Indic. 11, 1020-1026. https://doi.org/10.1016/j.ecolind.2011.01.006

Nathan, H.S.K., Reddy, B.S., 2012. Towards a conceptual framework for development of sustainable development indicators for an urban setup. Int. J. Sustain. Dev. 15, 187. https://doi.org/10.1504/IJSD.2012.047753

Nicholson, E., Collen, B., Barausse, A., Blanchard, J.L., Costelloe, B.T., Sullivan, K.M.E., Underwood, F.M., Burn, R.W., Fritz, S., Jones, J.P.G., McRae, L., Possingham, H.P., Milner-Gulland, E.J., 2012. Making Robust Policy Decisions Using Global Biodiversity Indicators. PLoS ONE 7, e41128. https://doi.org/10.1371/journal.pone.0041128

Olalla-Tárraga, M.Á., 2006. A conceptual framework to assess sustainability in urban ecological systems. Int. J. Sustain. Dev. World Ecol. 13, 1-15. https://doi.org/10.1080/13504500609469657

Phillis, Y.A., Kouikoglou, V.S., Verdugo, C., 2017. Urban sustainability assessment and ranking of cities. Comput. Environ. Urban Syst. 64, 254-265. https://doi.org/10.1016/j.compenvurbsys.2017.03.002

Pintér, L., Hardi, P., Bartelmus, P., 2005. Sustainable Development Indicators: Proposals for the Way Forward (prepared for the United Nations Division for Sustainable Development (UN-DSD)). International Institute for Sustainable Development (IISD), Winnipeg.

Pintér, L., Hardi, P., Martinuzzi, A., Hall, J., 2012. Bellagio STAMP: Principles for sustainability assessment and measurement. Ecol. Indic. 17, 20-28. https://doi.org/10.1016/j.ecolind.2011.07.001

Pope, J., Bond, A., Hugé, J., Morrison-Saunders, A., 2017. Reconceptualising sustainability assessment. Environ. Impact Assess. Rev. 62, 205-215. https://doi.org/10.1016/j.eiar.2016.11.002

Purvis, B., Mao, Y., Robinson, D., 2019. Three pillars of sustainability: in search of conceptual origins. Sustain. Sci. 14, 681-695. https://doi.org/10.1007/s11625-018-0627-5

Ramaswami, A., Weible, C., Main, D., Heikkila, T., Siddiki, S., Duvall, A., Pattison, A., Bernard, M., 2012. A Social-Ecological-Infrastructural Systems Framework for Interdisciplinary Study of Sustainable City Systems. J. Ind. Ecol. 16, 801-813. https://doi.org/10.1111/j.15309290.2012.00566.x

Ravitch, S.M., Riggan, M., 2017. Reason \& rigor: how conceptual frameworks guide research, Second edition. ed. SAGE, Los Angeles.

Rees, W., Wackernagel, M., 1996. Urban ecological footprints: Why cities cannot be sustainable-And why they are a key to sustainability. Environ. Impact Assess. Rev. 16, 223-248. https://doi.org/10.1016/S0195-9255(96)00022-4

Sébastien, L., Bauler, T., 2013. Use and influence of composite indicators for sustainable development at the EU-level. Ecol. Indic. 35, 3-12. https://doi.org/10.1016/j.ecolind.2013.04.014

Shen, J., Yang, X., 2014. Analyzing Urban Competitiveness Changes in Major Chinese Cities 1995-2008. Appl. Spat. Anal. Policy 7, 361-379. https://doi.org/10.1007/s12061-014-9114-2 
Smiciklas, J., Prokop, G., Stano, P., 2017. Collection Methodology for Key Performance Indicators for Smart Sustainable Cities. United for Smart Sustainable Cities (U4SSC). Retrieved from https://www.itu.int/en/publications/Documents/tsb/2017-U4SSC-CollectionMethodology/files/downloads/421318-CollectionMethodologyforKPIfoSSC-2017.pdf

Spangenberg, J.H., Pfahl, S., Deller, K., 2002. Towards indicators for institutional sustainability: lessons from an analysis of Agenda 21. Ecol. Indic., Hyatt S.I. 2, 61-77. https://doi.org/10.1016/S1470$160 \times(02) 00050-X$

Sustainable Society Foundation, 2014. Sustainable City Index - SCI-2014. Summary. Sustainable Society Foundation. Retrieved from http://www.ssfindex.com/ssi2016/wpcontent/uploads/pdf/Summary-SCI2014.pdf

Turnhout, E., 2009. The effectiveness of boundary objects: the case of ecological indicators. Sci. Public Policy 36, 403-412. https://doi.org/10.3152/030234209X442007

UN, 2019. World Urbanization Prospects - The 2018 Revision (ST/ESA/SER.A/420). United Nations, Department of Economic and Social Affairs, Population Division, New York.

UN, 2017. New Urban Agenda (A/RES/71/256). United Nations, Habitat III Secretariat, New York.

UN, 2015. Transforming our World: The 2030 Agenda for Sustainable Development (A/RES/70/1). United Nations. Retrieved from https://sustainabledevelopment.un.org/post2015/transformingourworld/publication

UN, 2014. Conference of European Statisticians recommendations on measuring sustainable development. United Nations Economic Commission for Europe, New York and Geneva.

UN, 2007. Indicators of Sustainable Development: Guidelines and Methodologies, 3rd ed. ed. United Nations, New York.

Valcárcel-Aguiar, B., Murias, P., Rodríguez-González, D., 2019. Sustainable Urban Liveability: A Practical Proposal Based on a Composite Indicator. Sustainability 11, 86. https://doi.org/10.3390/su11010086

van Oudenhoven, A.P.E., Petz, K., Alkemade, R., Hein, L., de Groot, R.S., 2012. Framework for systematic indicator selection to assess effects of land management on ecosystem services. Ecol. Indic. 21, 110-122. https://doi.org/10.1016/j.ecolind.2012.01.012

van Zeijl-Rozema, A., Ferraguto, L., Caratti, P., 2011. Comparing region-specific sustainability assessments through indicator systems: Feasible or not? Ecol. Econ. 70, 475-486. https://doi.org/10.1016/j.ecolecon.2010.09.025

Verma, P., Raghubanshi, A.S., 2018. Urban sustainability indicators: Challenges and opportunities. Ecol. Indic. 93, 282-291. https://doi.org/10.1016/j.ecolind.2018.05.007

Wang, Y., Lam, K., Harder, M.K., Ma, W., Yu, Q., 2013. Developing an indicator system to foster sustainability in strategic planning in China: A case study of Pudong New Area, Shanghai. Ecol. Indic. 29, 376-389. https://doi.org/10.1016/j.ecolind.2013.01.007

Wiek, A., Binder, C., 2005. Solution spaces for decision-making-a sustainability assessment tool for city-regions. Environ. Impact Assess. Rev. 25, 589-608. https://doi.org/10.1016/j.eiar.2004.09.009 
Wu, S., Li, D., Wang, X., Li, S., 2018. Examining component-based city health by implementing a fuzzy evaluation approach. Ecol. Indic. 93, 791-803. https://doi.org/10.1016/j.ecolind.2018.05.082

Xu, C., Wang, S., Zhou, Y., Wang, L., Liu, W., 2016. A Comprehensive Quantitative Evaluation of New Sustainable Urbanization Level in 20 Chinese Urban Agglomerations. Sustainability 8, 91. https://doi.org/10.3390/su8020091

Yigitcanlar, T., Dur, F., Dizdaroglu, D., 2015. Towards prosperous sustainable cities: A multiscalar urban sustainability assessment approach. Habitat Int., Measuring the Prosperity of Cities 45, 36-46. https://doi.org/10.1016/j.habitatint.2014.06.033 